\title{
Etiology of Central (Hypogonadotropic) Female Hypogonadism: Genetic, Organic and Functional Causes
}

\author{
Irena I* \\ Department of Endocrinology, Moscow Regional Research and Clinical Institute (MONIKI), Russia
}

Submission: October 30, 2017; Published: December 05, 2017

*Corresponding author: Irena Ilovayskaya, Department of Endocrinology, Moscow Regional Research and Clinical Institute (MONIKI), ul. Schepkina 61/2, korpus 9, Moscow, 129110 RU, Russia Tel: +7 49568486 97; +7 91667726 45; Email: irena.ilov@yandex.ru

\begin{abstract}
Central (hypogonadotropic) hypogonadism (CH) can be mentioned among the causes of menstrual and fertility problems in women. This clinical syndrome is characterized by decreased sex steroid secretion due to the impairment of basal and/or impulse secretion of gonadotropins. It can be congenital or acquired, organic or functional (i.e. without visible anatomic damages of the hypothalamo-hypophyseal area), isolated or combined with other pituitary hormone deficits (hypopituitarism). All causes of central female hypogonadism can be conditionally divided into some subgroups: genetic factors (lead to congenital $\mathrm{CH}$ ), organic factors (lead to acquired $\mathrm{CH}$ ), and idiopathic (lead functional $\mathrm{CH}$ ). Congenital $\mathrm{CH}$ can be caused by genes that control ontogenesis and migration of GnRH neurons, regulate secretion of GnRH and provide its' biological effects on gonadotropins. The potential organic causes of CH include pituitary tumors and some other types of tumors with similar localization, consequences of surgical or radiation intervention in connection with these tumors, brain injury as well as autoimmune, infiltrative and other rare diseases. Classical risk factors for functional $\mathrm{CH}$ include stress, excessive physical exercises and critically low body mass, however, variety of hormonal changes (including metabolic hormones) was observed and genetic predisposition was also shown for these patients. It is very important to understand complex pathogenetic factors that will help to improve diagnosis of this rare disease.
\end{abstract}

Keywords: Mondor's disease; Penis; Superficial venous thrombosis

Abbreviations: CH: Central (Hypogonadotropic) Hypogonadism; GnRH: Gonadotropin-Releasing Hormone; CNS: Central Nervous System; APAB: Antipituitary Antibodies; CRH: Corticotropin-Releasing Hormone; BMI: Body Mass Index

\section{Introduction}

Infertility and menstrual disturbances are the crucial problems of the modern society. Among the causes of menstrual and fertility problems in women central hypogonadism can be mentioned. This clinical syndrome is characterized by decreased sex steroid secretion due to the impairment of basal and/or impulse secretion of gonadotropins. In such cases inadequate production of FSH and LH is the leading pathogenic mechanism and in the majority of cases the ovary remains intact. This condition is also often called hypogonadotropic hypogonadism because gonadotropin concentrations are below the reference range in most of the patients. However, "low-normal" concentrations can also be observed, therefore the term "central hypogonadism" emphasizes that the central - i.e., hypothalamohypophyseal - regulation of ovarian function is damaged.

Central hypogonadism is a relatively rare condition that can be found approximately in $10 \%$ of women with primary amenorrhea [1,2] and $35 \%$ of women with secondary amenorrhea [3]. This disorder can be congenital or acquired, organic or functional (i.e., without visible anatomic damages of the hypothalamo-hypophyseal area), isolated or combined with other pituitary hormone deficits (hypopituitarism).

\section{Congenital central female hypogonadism (Genetic Factors)}

Congenital central hypogonadism can be caused by genetic defects at any level of a hypotalamo-hypophyseal axis: from disorders of gonadotropin-releasing hormone (GnRH) secretion to defects of gonadotropin molecular structure [412]. Occurrence of this syndrome is $1: 5.000-10.000$ in men and about 3-5 times less often in women. In our days it is known that central hypogonadism is a polygenic disease. Recent studies highlight the complexity of the mechanisms involved in the formation of the functional activity of the reproductive system as well as the contribution of various gene abnormalities to the pathogenesis of congenital central hypogonadism. The majority of cases are sporadic though various ways of inheritance also can be observed (auto some-dominant, auto some-recessive, 


\section{Global Journal of Reproductive Medicine}

X-linked). Genetic disorders are revealed in approximately 35\% of cases of isolated central hypogonadism. Other cases of the disease are considered as idiopathic (i.e., primary amenorrhea with decreased gonadotropin levels without visible anatomic damages of the hypothalamo-hypophyseal area and without detected genetic problems).

Genes associated with central hypogonadism can be conditionally divided into several groups [5-12]:

o Genes controlling ontogenesis and migration of GnRH neurons (the "neurodeveloping" genes)

o Genes regulating secretion and providing biological effect of GnRH (i.e., genes operating on the GnRH function).

\section{o Genes necessary for gonadotropic function.}

Loss of the main migration way due to the mutations of the neuro developing genes leads to the formation of Kallmann syndrome- a combination of insufficient GnRH secretion with disorders of the sense of smell (anosmia or hyposmia) that often is followed by other hereditary anomalies [7]. Recently, it was published that the incidence of the Kallmann syndrome in the Finnish population was 1 in 30,000 for males and 1 in 125,000 for females [13]. Products of genes ANOS1 (KAL1), FGFR1 and FGF8 as well as PROK2 and PROKR2, CHD7, NELF, HS6ST1 are responsible for migration of GnRH-neurons during embryogenesis as well as for the physiological development of the olfactory nerves and bulbs $[4,5]$. Mutations in these genes phenotypically are often associated with loss of olfactory bulbs.

Mutations in ANOS1 (coding protein anosmin 1) are found in $10-14 \%$ cases of Kallmann syndrome (sporadic or inhered, $\mathrm{X}$-linked type of inheritance) and are extremely rare in patients with low gonadotropin secretion and normal sense of smell. In such cases central hypogonadism and anosmia can be associated with bimanual synkinesis and renal anomalies [4,5,7]. Mutations in other neuro developing genes can be found in patients with anosmia as well as normosmia. Genes FGF8 (can be called KAL6) and FGFR1 (also called KAL2) are coding fibroblasts' growth factor type 8 and its' receptor $[4,5,10,12]$. Eleven types of fibroblasts' growth factors can active FGFR1, however, FGF8 is crucial for Kallmann syndrome development. Mutations in these genes (auto some-dominant type of inheritance) can be also associated with splitting of an upper lip or sky, ear anomalies, teeth dysgenesis. Genes PROK2 (or KAL4) and PROKR2 (KAL3) are coding prokineticin type 2 and its' receptor. Phenotypic signs associated with mutations in these genes (auto some-recessive type of inheritance) are very variable and can include obesity, sleep disturbances, synkinesis and epilepsy $[7,10,12]$. Gen CHD7 (KAL5) is coding chromo domain helicase DNA binding protein 7. Its' mutations lead to occurrence of CHARGE-syndrome (Colobomata, Heart Anomalies, choanal atresia, Retardation, Genital and Ear anomalies) but can be also found in patients with central hypogonadism without anosmia and this severe syndrome $[4,12]$. Mutations in NELF (coding nasal embriogenic LHRH-factor) and HS6ST1 (coding geparan- sulfat-6-0-sulfotransferase) can be also responsible for central hypogonadism with/without anosmia. Phenotypically other clinical signs are not observed. Supposed type of inheritance is autosome-recessive [12].

Genes KISS1/KISSR1 (coding kisspeptin and its' receptor), LEP/LEPR (coding leptin and its receptor), TAC3/TACR3 (coding neurokinin B and its receptor) and PCSK1 (coding neuroendocrine convertase type 1) are responsible for the regulation of synthesis of GnRH $[4,5,8,10]$. Mutations in all these genes have auto somerecessive type of inheritance and have no other clinical sings besides central hypogonadism. Mutations in KISS1R gene are a possible but extremely rare reason for central hypogonadism. Mutations in this gene lead to a significant decrease of $\mathrm{LH}$ impulse amplitude without changes of impulse rate and are found in patients with normosmic central hypogonadism [8]. Recently, 18 new genes-candidates have been revealed which probably participate in the formation of normosmic idiopathic central hypogonadism [14]. Thus, number of genes responsible for the development of central female hypogonadism will increase. Genes GNRH1/GNRHR are the main modulators for its biological action $[8,10,12]$. Products of these genes influence gonadotropic production only, so mutations in GNRH1/GNRHR should not be accompanied with other phenotypic implications except hypogonadism itself.

Mutations in DAX1 gene lead to both decrease in hypothalamic GnRH secretion and impairment of the development of gonadotrophs [5]. Besides DAX-1, couples ligand-receptor LHB/LHR and FSHB/FSHR regulate secretion of LH and FSH, respectively. The gonadotropin deficiency can be caused by violation of $\beta$-subunit synthesis of LH (LHB gene) and FSH (FSHB gene) as the $\beta$-subunit defines specific properties of hormones (receptor recognition, immune properties, etc). Mutations in LHB gene lead to an ovulation, mutations in FSHB gene - to primary amenorrhea $[5,6]$. There are also some genes that are responsible for the development of congenital hypopituitarism (i.e., Pit-1, Prop-1), but they are not considered in detail in this review.

\section{Acquired central female hypogonadism (Organic Factors)}

Pituitary tumors as well as some other types of tumors of central nervous system (CNS) which are localized in hypothalamo-hypophyseal area, consequences of surgical or radiation intervention in connection with these tumors, brain injury as well as autoimmune, infiltrative and other rare diseases can be enumerated among the potential organic causes of central hypogonadism. It is possible to note an increase in the number of patients with organic causes of central hypogonadism over the past decades. Due to the modern diagnostic and treatment technics that have been applied to clinical practice a considerable improvement in the early detection of pituitary tumors and more favorable outcomes after treatment are observed. Transnasal adenomectomy is a leading method of treatment that is applicable in $90-95 \%$ of patients with pituitary lesions and it 


\section{Global Journal of Reproductive Medicine}

is not an injuring intervention in comparison with transcranial operations. Therefore women who underwent neurosurgery not only keep working capacity, but also set targets of restoration of the menstrual and reproductive functions for the doctor.

Non-functioning pituitary tumors are associated with hypogonadism in $40-45 \%$ of cases $[15,16]$. Clinical manifestations develop more often when pituitary tumor volume is $>1000 \mathrm{~mm} 3$ and extrasellar tumor expansion with compression of pituitary stalk is observed [15]. Hypothalamic regulation of the pituitary function is broken and the atrophy of adenopituitary develops with the gonadotropic deficiency as the first symptom. An increase of intracranial pressure directly in the sellar cavity is also a pathogenic factor of hypopituitarism development [17]. Prolactin-secreting tumors are followed by hypogonadism very often - up to $95 \%$ of cases [18]. However, hypogonadal symptoms are reversible on dopamine agonists' therapy in $88-92 \%$ of cases. Somatotropinomas (GH-secreting pituitary tumors) are accompanied with hypogonadism in $32-87 \%$ of cases and among women of reproductive age with this disease the menstrual and/ or fertility problems are one of the first symptoms of GH excess in $36 \%$ cases $[19,20]$. Central hypogonadism can also be a result of neurosurgical treatment and/or radiation of pituitary tumors.

The frequency of postoperative hypopituitarism (including central hypogonadism) after neurosurgical intervention on average does not exceed $5.5 \%$ in the specialized centers [21]. Nevertheless, the frequency of hypopituitarism increases with pituitary tumor size $>20 \mathrm{~mm}$. The development of hypopituitarism after radiation of hypothalamo-hypophyseal area depends on the size and morphological features of pituitary lesions, a dose of beam loading and on the type of radiation [22]. After convection radiation therapy in a dose over 30 Gycentral hypogonadism develops in 30-60\% cases [23]. Most often (up to $70 \%$ of cases in 10-15 years after beam loading) hypopituitarism develops after cranial radiation concerning malignant tumors of the head and neck as considerable doses of gamma-irradiation $120-180$ Gy are used $[24,25]$. Recently radio surgical methods of the treatment of pituitary tumors have started to be used more widely. In 3-5 years after gamma knife in an average dose of 15Gy different types of hypopituitarism including hypogonadism are noted in $22 \%$ of patients [26].

The most frequently observed CNS tumors of this area are craniopharyngiomas. These tumors account for up to $20 \%$ of all tumors of this localization revealed in adults, and they can be both extra-, and intrapituitary $[27,28]$. The embryogenesis of craniopharyngioma causes its close anatomo-functional connection with hypothalamic nuclei and pituitary so this can explain the high frequency of associated pituitary deficits. Clinical and hormonal symptoms of hypogonadism are usually found in $56-87 \%$ of patients with craniopharyngioma, and reproductive dysfunction quite often develops several years prior to the progress of neurologic symptoms [27]. Moreover, after craniopharyngioma neurosurgery hypopituitarism develops in additionally $18-31 \%$ of patients without initial hormonal disorders [29,30]. Other CNS tumors of similar anatomic localization (for example, gliomas, hordomas) are associated with hypogonadism in $10-23 \%$ of cases [31].

Central hypogonadism can stem from autoimmune damage of a pituitary - the so-called lymphocytic hypopysitis. A diffusion infiltration of pituitary tissue with lymphocytes and lymphoid elements occurs and the destruction of normal pituitary cells develops [32]. Headaches and visual field impairment, weakness and fatigue are the main signs of the initial stage of the disease; symmetrical pituitary enlargement with a protuberance of the upper contour is noted on MR-images [33]. Full or partial loss of functions of adeno and/or neurohypophysis can develop at a later stage [34,35], in some cases- with "empty" sella turcica formation [33]. The presence of antibodies to surface and/or cytoplasmic antigens of adenopituitary cells in blood stream is considered as a marker of autoimmune damage of the pituitary [35]. It was shown that antipituitary antibodies (APAB) are found statistically significant more often in patients with central hypogonadism than in healthy population [36-38]. It could be considered as the evidence of involvement of humoral autoimmunity in pathogenesis of hypopituitarism. There is a point of view that lymphocytic hypophysitisis not rare but an underestimated disease [39].

It was shown that new biological and immune modulatory agents recently introduced into clinical practice are related hypophysitis (i.e., hypophysitis is a distinctive side effect of treatment with cytotoxic T-lymphocyte antigen-4 antibodies) [40]. Brain injuries can also be the cause of the loss of functions of an adenopituitary. Many experts recommend to examine patients within 12 months after a moderate/severe brain injury for hypopituitarism [41,42]. The clinical picture of post-traumatic hypopituitarism has no fundamental differences from a classical variant [43]. Pituitary functions can be partially restored on specific treatment for brain injury, however hypopituitarism is found in $17-23 \%$ of patients in 12 months after the trauma [44]. The frequency of post-traumatic hypopituitarism is 2-3 times higher in the presence of APAB than without them. Therefore autoimmune mechanisms can also participate in the formation of this complication $[44,45]$.

It is well known that gonadotropin insufficiency can be observed in women who had massive blood loss in the early postnatal period (Sheehan's syndrome). The frequency of Sheehan's syndrome is $0.1 \%$ in general population but it comes up to $40 \%$ after massive postnatal or post-abortion bleedings $[46,47]$. Sheehan's syndrome develops in $25 \%$ of women after $600-800 \mathrm{ml}$ blood loss, in $50 \%$ - after $900-1000 \mathrm{ml}$ blood loss and in $75 \%$-after massive blood loss over $1000 \mathrm{ml}$ [48]. The ischemic necrosis of the pituitary leads to the destruction of the pituitary cells. However, possible autoimmune mechanisms of pituitary damage also could take place: the frequency of antihypothalamic and antipituitary antibodies in patients with Sheehan's syndrome is $35 \%$ that is essentially more often than in general population (up to 1\%) [49]. The rare infiltrative diseases such 


\section{Global Journal of Reproductive Medicine}

as hemochromatosis, xanthomatosis, sacroidosis can contribute to the development of gonadotropin insufficiency [50-53]. In such cases, central hypogonadism can be reversible, and the treatment of the main disease (for example, hemochromatosis) can restore gonadotropic function.

\section{Functional central female hypogonadism (metabolic, hormonal and genetic factors)}

Functional gonadotropic insufficiency is a cause of about $35 \%$ of cases of secondary amenorrhea [10,54,55]. The term "functional" means that there are no organic lesions of hypothalamus and/or pituitary. It is often called "functional hypothalamic amenorrhea". The cornerstone of this condition is a disorder of pulse GnRH secretion that results in the impairment of gonadotropin pulse secretion: rare $\mathrm{LH}$ and $\mathrm{FSH}$ pulses, diminishment of their amplitudes, a combination of impaired frequency and amplitude of impulses, total absence of impulses and decreased basal secretion of gonadotrophins were described [55-57]. Offered diagnostic criteria of functional gonadotropic insufficiency describe the absence of menstrual periods for over 6 months on the background of low or "lownormal" $(<5 \mathrm{mU} / \mathrm{l})$ concentration of LH and FSH [55]. There are classical risk factors for functional central hypogonadism that include stress, excessive physical exercises and critically low body mass $[10,54,55]$. It is assumed that all this factors lead to disorders of secretion of various neuropeptides: first of all, neuropeptid Y (NPY), corticotropin-releasing hormone (CRH), leptin, ghrelin and $\beta$-endorphin $[54,55,58]$.

The stress-induced ("psychogenic") amenorrhea is one of the most common causes of functional gonadotropic insufficiency $[59,60]$. In these cases CRH plays an important pathophysiological role. Its secretion increases during acute and/or chronic stress that directly and indirectly suppresses electrophysiological activity of the GnRH pulse generator [61]. Increased CRH secretion also stimulates $\beta$-endorphin production possessing the independent inhibiting action hypothalamohypophyseal-ovarian axis [59]. CRH and cortisol secretion is higher in women with functional central hypogonadismin comparison with healthy women [61]. This fact is considered as indirect confirmation of a chronic stress, on the one hand, and as an additional factor of disturbance of GnRH/gonadotrophins secretion, on the other hand. Decrease in ACTH and cortisol emission in response to stimulation by exogenous CRH was also observed in women with stress-induced amenorrhea [59] that can be the evidence of compensatory decrease in sensitivity to $\mathrm{CRH}$ in the conditions of its overproduction. Some researchers assume that CRH antagonists could be used for stressinduced amenorrhea in the future [55]. Increased activation of hypothalamo-hypophyseal-adrenal axis is noted also in women with amenorrhea due to anorexia nervosa [62].

Menstrual cycle disturbances accompany low body weight. In 1974 it was hypothesized that normal menstrual function can occur when the part of fatty tissue in the female body is $>17 \%$, and the ovulation - when the part of fatty tissue in the female body is $>22 \%$ [63]. Authors have considered gonadotropic insufficiency as protective reaction to restriction of food because the metabolism of potential mother organism went only for her own survival. In cases of decreased body weight (moderated - 10$15 \%$ from ideal, critical - more than $30 \%$ ) peripheral metabolism and functional activity of sexual steroids is broken [64].

Further studies have shown that hormonal activity of adipocytes is not limited to metabolism of sex steroids, but also includes the secretion of some metabolic hormones that regulate reproductive function (for example: leptin, ghrelin, etc.). The concentration of leptin correlates with the body weight, the body mass index (BMI), and the percentage of fatty tissue [65]. On the other hand, women with amenorrhea had lower leptin concentration in comparison with healthy women of the same age, body weight and content of fatty tissue in an organism [55]. An increase in body weight by $1 \mathrm{~kg}$ leads to fast increase in leptin concentration [65]. Decrease in mass of fatty tissue in women with functional central hypogonadism is the most important factor of lessening of leptin concentration. It was noted that functional gonadotropic deficiency was found less frequently in BMI ranging from 18 up to $25 \mathrm{~kg} / \mathrm{m} 2$ than in patients with $\mathrm{BMI}<17 \mathrm{~kg} / \mathrm{m} 2$ [65]. Low leptin concentration is followed by alteration of pulse LH secretion [66]. Besides, the hypoleptinemia leads to the activation of adrenergic system and rise of CRH and NPY secretion.

In turn, this stimulates secretion of ACTH and cortisol that is an additional factor of suppression of GnRH/LH secretion [65]. There are publications about successful treatment of functional hypothalamic amenorrhea with recombinant leptin [67]. It once again emphasizes the importance of leptin in the regulation of the reproductive function. Low basal concentration of NPY was also observed in patients with functional hypothalamic amenorrhea [58]. It is assumed that NPY could be the major candidate for a role of the coordinator between food and reproduction at the CNS level [68]. Spontaneous incidental increase in the frequency of NPY impulses in women with amenorrheais followed by more frequent LH impulses [69]. Another participant of pathogenesis of functional amenorrhea at loss of body weight is ghrelin. Ghrelin concentrations correlate reversely with BMI and androgen levels $[69,70]$. High ghrelin concentrations have been noted after the loss of the body weight induced by a diet or surgical intervention as well as during inadequate eating behaviour (even in eucaloric state) and negative energetic balance [71,72] Ghrelin levels were much higher in women with functional central hypogonadism than in healthy women [73]. As ghrelin suppresses the activity of hypothalamo-hypophyseal-gonadal axis, its high concentrations can be the cause of persistent amenorrhea after normalization of the body weight and leptin concentration [73].

Excessive physical activity (including professional sport) is another reason for functional amenorrhea. Increased levels of $\mathrm{CRH}, \beta$-endorphin and ghrelin as well as extremely low leptin concentration were noted in exercising patients with 


\section{Global Journal of Reproductive Medicine}

amenorrhea [74]. In these patients NPY secretion is notably suppressed as in patients with the loss of body weight. Excessive production of CRH is also observed. The activation of opioidergic system is more expressed in amenorrheic women with stress and physical activities that loss of the body weight [55]. Recently it has been shown that genetic mutations are also found in patients with functional hypothalamic amenorrhea (functional central hypogonadism) [75]. Normal menarche is not an evident clinical sign of the absence of genetic mutations of the "reproductive" genes. Known risk factors are crucial first of all for women with genetic predisposition. Menstrual disturbances including amenorrhea are found not in ALL women with stressful events, excessive physical activities and/or low body weight. Moreover, in some women with menstrual abnormalities spontaneous recovery of regular menstrual cycle can be observed after elimination of risk factors. However, in patients with some types of genetic mutations amenorrhea persists despite normalization of body weight, disappearance of stress and/or decreased physical exercises. Changes in the mRNA expression of some "reproductive" genes have been demonstrated in patients with functional central hypogonadism [76].

\section{Conclusion}

Central female hypogonadism is a multifactorial disorder that can be found in women with primary or secondary amenorrhea, with or without hypothalamo-pituitary lesions. It is very important to make a right diagnosis of this disorder because it has a negative impact on women's health. It is not just "amenorrhea". Unfavorable changes of lipid and mineral metabolism, decreased bone mass and some other negative effects including worsening of life quality were described in women with central hypogonadism $[77,78]$. So it is very important to understand complex pathogenetic factors that will help to improve diagnosis of this rare disease.

\section{References}

1. Marsh CA, Grimstad FW (2014) Primary amenorrhea: diagnosis and management. Obstet Gynecol Surv 69(10): 603-612.

2. Tanmahasamut $P$, Rattanachaiyanont $M$, Dangrat $C$, Indhavivadhana $S$, Angsuwattana S, et al. (2012) Causes of primary amenorrhea: a report of 295 cases in Thailand. J Obstet Gynaecol Res 38(1): 297-301.

3. Genazzani AD, Chierchia E, Santagni S, Rattighieri E, Farinetti A, et al. (2010) Hypothalamic amenorrhea: from diagnosis to therapeutical approach. Ann Endocrinol (Paris) 71(3): 163-169.

4. Semple RK, Topaloglu AK (2010) The recent genetics of hypogonadotrophic hypogonadism - novel insights and new questions. Clin Endocrinol (Oxf) 72(4): 427-435.

5. Topaloglu AK, Kotan LD (2016) Genetics of Hypogonadotropic Hypogonadism. Endocr Dev 29: 36-49.

6. Beate K, Joseph N, Nicolas de R, Wolfram K (2012) Genetics of isolated hypogonadotropic hypogonadism: role of GnRH receptor and other genes. Int J Endocrinol 2012: 1-9.

7. Wierman ME, Kiseljak-Vassiliades K, Tobet S (2011) Gonadotropinreleasing hormone $(\mathrm{GnRH})$ neuron migration: initiation, maintenance and cessation as critical steps to ensure normal reproductive function. Front Neuroendocrinol 32(1): 43-52.
8. Semple RK, Topaloglu AK (2010) Neurokinin B and its receptor in hypogonadotropic hypogonadism. Front Horm Res 39: 133-141.

9. Mengen E, Tunc S, Kotan LD, Nalbantoglu O, Demir K, et al. (2016) Complete Idiopathic Hypogonadotropic Hypogonadism due to Homozygous GNRH1 Mutations in the Mutational Hot Spots in the Region Encoding the Decapeptide. Horm Res Paediatr 85(2): 107-111.

10. Vezzoli V, Duminuco P, Bassi I, Guizzardi F, Persani L, et al. (2016) The complex genetic basis of congenital hypogonadotropic hypogonadism. Minerva Endocrinol 41(2): 223-239.

11. Hutchins BI, Kotan LD, Taylor-Burds C, Ozkan Y, Cheng PJ, et al. (2016) CCDC141 Mutation Identified in Anosmic Hypogonadotropic Hypogonadism (Kallmann Syndrome) Alters GnRH Neuronal Migration. Endocrinology 157(5): 1956-1966.

12. Eneva NG, Nefedova LN, Loktionova AS, Ilovayskaya IA, Kim AI (2014) The role of the genetic factors in pathogenesis of hypogonadotropic hypogonadism. Problems of endocrinology 60(6): 38-44.

13. Laitinen EM, Vaaralahti K, Tommiska J, Eklund E, Tervaniemi M, et al. (2011) Incidence, phenotypic features and molecular genetics of Kallmann syndrome in Finland. Orphanet J Rare Dis 6: 41.

14. Quaynor SD, Bosley ME, Duckworth CG, Porter KR, Kim SH, et al. (2016) Targeted next generation sequencing approach identifies eighteen new candidate genes in normosmic hypogonadotropic hypogonadism and Kallmann syndrome. Mol Cell Endocrinol 437: 86-96.

15. Pereira AM, Biermasz NR (2012) Treatment of nonfunctioning pituitary adenomas: what were the contributions of the last 10 years? A critical view. Ann Endocrinol (Paris) 73(2): 111-116.

16. Shao S, Li X (2013) Clinical features and analysis in 1385 Chinese patients with pituitary adenomas. J Neurosurg Sci 57(3): 267-275.

17. Arafah BM, Prunty D, Ybarra J, Hlavin ML, Selman WR (2000) The dominant role of increased intrasellar pressure in the pathogenesis of hypopituitarism, hyperprolactinemia, and headaches in patients with pituitary adenomas. J Clin Endocrinol Metab 85(5): 1789-1793.

18. Romijn JA (2014) Hyperprolactinemia and prolactinoma. Handb Clin Neurol 124: 185-195.

19. Logutova L, Zaydieva J, Dreval A, Chechneva M, Ilovayskaya I, et al (2014) Gynecologic problems in women with acromegaly. Giornale italiano ostetricia e ginecologia XXXVI(1): 190-193.

20. Grynberg M, Salenave S, Young J, Chanson P (2010) Female gonadal function before and after treatment of acromegaly. J Clin Endocrinol Metab 95(10): 4518-4525.

21. Fatemi N, Dusick JR, Mattozo C, McArthur DL, Cohan P, et al. (2008) Pituitary hormonal loss and recovery after transsphenoidal adenoma removal. Neurosurgery 63(4):709-718.

22. Fernandez A, Brada M, Zabuliene L, Karavitaki N, Wass JA (2009) Radiation-induced hypopituitarism. Endocr Relat Cancer 16(3): 733772.

23. Li X, Li Y, Cao Y, Li P, Liang B, et al. (2017) Safety and efficacy of fractionated stereotactic radiotherapy and stereotactic radiosurgery for treatment of pituitary adenomas: A systematic review and metaanalysis. J Neurol Sci 372: 110-116.

24. Kyriakakis N, Lynch J, Orme SM, Gerrard G, Hatfield P, et al. (2016) Pituitary dysfunction following cranial radiotherapy for adult-onset nonpituitary brain tumours. Clin Endocrinol (Oxf) 84(3): 372-379.

25. Taku N, Gurnell M, Burnet N, Jena R (2017) Time Dependence of Radiation-induced Hypothalamic-Pituitary Axis Dysfunction in Adults Treated for Non-pituitary, Intracranial Neoplasms. Clin Oncol (R Coll Radiol) 29(1): 34-41.

26. Starke RM, Williams BJ, Jane JA, Sheehan JP (2012) Gamma Knife surgery for patients with nonfunctioning pituitary macroadenomas: 


\section{Global Journal of Reproductive Medicine}

predictors of tumor control, neurological deficits, and hypopituitarism. J Neurosurg 117(1): 129-135.

27. Erfurth EM (2015) Endocrine aspects and sequel in patients with craniopharyngioma. J Pediatr Endocrinol Metab 28(1-2): 19-26.

28. Karavitaki N (2014) Management of craniopharyngiomas. J Endocrinol Invest. 37(3): 219-28.

29. Dusick JR, Fatemi N, Mattozo C, McArthur D, Cohan P, et al. (2008) Pituitary function after endonasal surgery for nonadenomatous parasellar tumors: Rathke's cleft cysts, craniopharyngiomas, and meningiomas. Surg Neurol 70(5): 482-490.

30. Erfurth EM, Holmer H, Fjalldal SB (2013) Mortality and morbidity in adult craniopharyngioma. Pituitary 16(1): 46-55.

31. Valassi E, Biller BM, Klibanski A, Swearingen B (2010) Clinical features of nonpituitary sellar lesions in a large surgical series. Clin Endocrinol (Oxf) 73(6): 798-807.

32. Karaca Z, Kelestimur F (2016) The management of hypophysitis. Minerva Endocrinol 41(3): 390-319.

33. Faje A (2016) Hypophysitis: Evaluation and Management. Clin Diabetes Endocrinol 2: 15.

34. Abe T (2008) Lymphocytic infundibulo-neurohypophysitis and infundibulo-panhypophysitis regarded as lymphocytic hypophysitis variant. Brain Tumor Pathol 25(2): 59-66.

35. Bellastella G, Maiorino MI, Bizzarro A, Giugliano D, Esposito K, et al (2016) Revisitation of autoimmune hypophysitis: knowledge and uncertainties on pathophysiological and clinical aspects. Pituitary 19(6): 625-642.

36. Khare S, Jagtap VS, Budyal SR, Kasaliwal R, Kakade HR, et al. (2015) Primary (autoimmune) hypophysitis: a single centre experience. Pituitary 18(1): 16-22.

37. de Graaff LC, De Bellis A, Bellastella A, Hokken-Koelega AC (2009) Antipituitary antibodies in Dutch patients with idiopathic hypopituitarism. Horm Res 71(1): 22-27.

38. Ilovayskaya IA, Zektser VY, Keda YM, Dreval AV, Marova EI (2013) Human autoimmunity and reproductive disorders. Giornale italiano ostetricia e ginecologia XXXV(1): 229-231.

39. Tuğcu B, Gunaldi O, Postalci L, Tanriverdi O, Ofluoglu E, et al. (2011) Lymphocytic hypophysitis: an underestimated disease affecting the sellar region. Neurol Neurochir Pol 45(2): 174-179.

40. Angelousi A, Chatzellis E, Kaltsas G (2017) New molecular, biological, and immunological agents inducing hypophysitis. Neuroendocrinology.

41. Karaca Z, Tanrıverdi F, Ünlühızarcı K, Kelestimur F (2016) GH and Pituitary Hormone Alterations After Traumatic Brain Injury. Prog Mol Biol Transl Sci 138: 167-191.

42. Karamouzis I, Pagano L, Prodam F, Mele C, Zavattaro M, et al. (2016) Clinical and diagnostic approach to patients with hypopituitarism due to traumatic brain injury (TBI), subarachnoid hemorrhage (SAH), and ischemic stroke (IS). Endocrine 52(3): 441-450.

43. Klose M, Feldt-Rasmussen U (2015) Hypopituitarism in Traumatic Brain Injury-A Critical Note. J Clin Med 4(7): 1480-1497.

44. Tanriverdi F, Kelestimur F (2015) Pituitary dysfunction following traumatic brain injury: clinical perspectives. Neuropsychiatr Dis Treat 11: 1835-1843.

45. Guaraldi F, Grottoli S, Arvat E, Ghigo E (2015) Hypothalamic-Pituitary Autoimmunity and Traumatic Brain Injury. J Clin Med 4(5): 1025-1035.

46. Diri H, Karaca Z, Tanriverdi F, Unluhizarci K, Kelestimur F (2016) Sheehan's syndrome: new insights into an old disease. Endocrine 51(1): 22-31.

47. Kilicli F, Dokmetas HS, Acibucu F (2013) Sheehan's syndrome. Gynecol Endocrinol 29(4): 292-295.
48. Karaca Z, Laway BA, Dokmetas HS, Atmaca H, Kelestimur F (2016) Sheehan syndrome. Nat Rev Dis Primers 2: 16092.

49. De Bellis A, Kelestimur F, Sinisi AA, Ruocco G, Tirelli G, et al. (2008) Anti-hypothalamus and anti-pituitary antibodies may contribute to perpetuate the hypopituitarism in patients with Sheehan's syndrome. Eur J Endocrinol 158(2): 147-152.

50. Fraietta R, Zylberstejn DS, Esteves SC (2013) Hypogonadotropic hypogonadism revisited. Clinics (Sao Paulo) 68(Suppl 1): 81-88.

51. Hanna B, Li YM, Beutler T, Goyal P, Hall WA (2015) Xanthomatous hypophysitis. J Clin Neurosci 22(7): 1091-1097.

52. Pelusi C, Gasparini DI, Bianchi N, Pasquali R (2016) Endocrine dysfunction in hereditary hemochromatosis. J Endocrinol Invest 39(8): 837-847.

53. Langrand C, Bihan H, Raverot G, Varron L, Androdias G, et al. (2012) Hypothalamo-pituitary sarcoidosis: a multicenter study of 24 patients. QJM 105(10): 981-995.

54. Fourman LT, Fazeli PK (2015) Neuroendocrine causes of amenorrhea an update. J Clin Endocrinol Metab 100(3): 812-824.

55. Meczekalski B, Podfigurna-SA, Warenik-SA, Genazzani AR (2008) Functional hypothalamic amenorrhea: current view on neuroendocrine aberrations. Gynecol Endocrinol 24(1): 4-11.

56. Perkins RB, Hall JE, Martin KA (1999) Neuroendocrine abnormalities in hypothalamic amenorrhea: spectrum, stability, and response to neurotransmitter modulation. J Clin Endocrinol Metab. 84(6): 19051911.

57. Ilovayskaya IA, Zektser VY, Mikhaylova DS, Donina EY, Goncharov NP, et al. (2008) The functional state of the hypothalamic-hypophyseal - ovarian system in women with central hypogonadism. Voprosy ginekologii, akusherstva i perinatalogii 7(5): 22-28.

58. Celik O, Aydin S, Celik N, Yilmaz M (2015) Peptides: Basic determinants of reproductive functions. Peptides 72: 34-43.

59. Berga SL, Loucks TL (2005) The diagnosis and treatment of stressinduced anovulation. Minerva Gynecol 57(1): 45-54.

60. Schliep KC, Mumford SL, Vladutiu CJ, Ahrens KA, Perkins NJ, et al. (2015) Perceived stress, reproductive hormones, and ovulatory function: a prospective cohort study. Epidemiology 26(2): 177-184.

61. Genazzani AD (2005) Neuroendocrine aspects of amenorrhea related to stress. Pediatr Endocrinol Rev 2(4): 661-668.

62. Monteleone P, Scognamiglio P, Monteleone AM, Perillo D, Maj M (2014) Cortisol awakening response in patients with anorexia nervosa or bulimia nervosa: relationships to sensitivity to reward and sensitivity to punishment. Psychol Med 44(12): 2653-2660.

63. Frisch RE, McArthur JW (1974) Menstrual cycles: fatness as a determinant of minimum weight for height necessary for their maintenance or onset. Science 185(4155): 949-951.

64. Frisch RE (1990) The right weight: body fat, menarche and ovulation. Baillieres Clin Obstet Gynaecol 4(3): 419-439.

65. Nestor CC, Kelly MJ, Rønnekleiv OK (2014) Cross-talk between reproduction and energy homeostasis: central impact of estrogens, leptin and kisspeptin signaling. Horm Mol Biol Clin Investig 17(3): 109-128.

66. Tena-Sempere M (2013) Interaction between energy homeostasis and reproduction: central effects of leptin and ghrelin on the reproductive axis. Horm Metab Res 45(13): 919-927.

67. Chou SH, Chamberland JP, Liu X, Matarese G, Gao C, et al. (2011) Leptin is an effective treatment for hypothalamic amenorrhea. Proc Natl Acad Sci USA 108(16): 6585-6590. 
68. Muroi Y, Ishii T (2016) A novel neuropeptide Y neuronal pathway linking energy state and reproductive behavior. Neuropeptides 59: 1-8.

69. Meczekalski B, Genazzani AR, Genazzani AD, Warenik-SA, Luisi M (2006) Clinical evaluation of patients with weight loss-related amenorrhea: neuropeptide $\mathrm{Y}$ and luteinizing hormone pulsatility. Gynecol Endocrinol 22(5): 239-243.

70. Pagotto U, Gambineri A, Vicennati V, Heiman ML, Tschöp M, et al. (2002) Plasma ghrelin, obesity, and the polycystic ovary syndrome: correlation with insulin resistance and androgen levels. J Clin Endocrinol Metab 87(12): 5625-5629.

71. Schneider LF, Monaco SE, Warren MP (2008) Elevated ghrelin level in women of normal weight with amenorrhea is related to disordered eating. Fertil Steril 90(1): 121-128.

72. Cummings DE, Weigle DS, Frayo RS, Breen PA, Ma MK, et al. (2002) Plasma ghrelin levels after diet-induced weight loss or gastric bypass surgery. N Engl J Med 346(21): 1623-1630.

73. Tolle V, Kadem M, Bluet-PMT, Frere D, Foulon C, et al. (2003) Balance in ghrelin and leptin plasma levels in anorexia nervosa patients and constitutionally thin women. J Clin Endocrinol Metab 88(1): 109-116.
74. Scheid JL, De Souza MJ (2010) Menstrual irregularities and energy deficiency in physically active women: the role of ghrelin, PYY and adipocytokines. Med Sport Sci 55: 82-102.

75. Caronia LM, Martin C, Welt CK, Sykiotis GP, Quinton R, et al. (2011) A Genetic Basis for Functional Hypothalamic Amenorrhea. N Eng J Med 364(3): 215-225.

76. Eneva NG, Nefedova LN, Loktionova AS, Khusniyarova KA, Ilovayskaya IA, et al. (2017) On the problem of female infertility: A search for genetic markers. Zh Obshch Biol 78(2): 3-13.

77. Meczekalski B, Katulski K, Czyzyk A, Podfigurna SA, Maciejewska JM (2014) Functional hypothalamic amenorrhea and its influence on women's health. J Endocrinol Invest 37(11): 1049-1056.

78. Ilovayskaya I, Zektser V, Lazebnik L (2017) Similarity of female central (hypogonadotropic) hypogonadism and postmenopause. Climacteric 20(4): 356-361. 